\title{
Mechanical Properties of Nitrided Layer after Laser Modification
}

\author{
Dominika Panfil-Pryka ${ }^{1 *}$, Michał Kulka ${ }^{1}$ \\ ${ }^{1}$ Poznan University of Technology, Institute of Materials Science and Engineering, Pl. M.Sklodowskiej-Curie 5, \\ 60-965 Poznan, Poland
}

Received: March 10, 2021; Accepted: March 20, 2021; Published: March 27, 2021

*Corresponding author: Dominika Panfil-Pryka, 1Poznan University of Technology, Institute of Materials Science and Engineering, Pl. M.SklodowskiejCurie 5, 60-965 Poznan, Poland, E-mail: dominika.panfil-pryka@put.poznan.pl

\begin{abstract}
The aim of this work was to study the microstructure and friction coefficient of hybrid surface layers, produced by a controlled gas nitriding and laser modification. Nitriding is well-known technique of thermo-chemical treatment, applied in order to produce the surface layers of improved hardness and wear resistance. The phase composition and growth kinetics of the diffusion layer can be controlled using a gas nitriding with changeable nitriding potential. $42 \mathrm{CrMo} 4$ steel was treated by composite technology of gas nitriding and laser hardening. The nitriding processes were carried out at temperature of $580^{\circ} \mathrm{C}$ for $8 \mathrm{~h}$. Next, the nitrided layer was laser-modified using laser TRUMPF TruDiode 3006 with maximal power of $3 \mathrm{~kW}$ using the two laser beam powers (P): $0.53 \mathrm{~kW}$ and $0.62 \mathrm{~kW}$. Then, the microstructure and properties of the laser-modified nitrided layers were investigated using optical microscopy, Vickers hardness tester and friction wear testing machine. The nitrided layers were subjected to wear tests using a ball-on-disc method at room temperature. The results showed that the microstructure of the produced hybrid layers consisted of the re-melted and heat-affected zones in which martensite mainly occurred. Additional laser treatment effectively increased the hardness, especially in heat-affected zone, as well as the depth of the hardened layer. The layer after modification laser hest tretment were good friction coefficien. The curve of the friction coefficient after the nitrided layer was characterized by large fluctuations. Compared with nitriding technology , the hybrid treatment technology can effectively increase the hardness and wear resistance of the $42 \mathrm{CrMo} 4$ steel surface. The effect of LHT on the tribological properties was ambiguous. Although the relatively low value of the average friction coefficient $(0.46)$ was calculated for nitrided layer, the course of friction coefficient was characterized by large fluctuations and the extended grinding-in time. Simultaneously, the course of friction coefficient was very smooth after nitriding and LHT. However, the average friction coefficient were higher, obtaining 0.60 and 0.57 for the hybrid layers, produced using $\mathrm{P}=530 \mathrm{~W}$ and $\mathrm{P}=620 \mathrm{~W}$, respectively.
\end{abstract}

Keywords: Nitriding; Laser Heat Treatment; Microstructure; Wear Resistance; Microhardness

\section{Introduction}

Laser surface modification is increasingly used in industrial applications. Laser hardening or laser alloying with different elements greatly increased the hardness and wear resistance of machine parts, especially those containing carbides, nitrides and borides $[1,4]$. Laser hardening is a surface process with some peculiar characteristics such as that it does not require a quenching medium and it can be more selective if compared to the classical treatments carried out in an oven or by induction hardening [2,3]. Laser materials processing can be carried out in three different ways: without re-melting, with re-melting or with vaporization. Such a treatment is usually performed to improve the wear characteristics of materials [1].

Nitriding process is well-known as a method of surface treatment which improves wear resistance properties [4]. Therefore, in recent years the controlled gas nitriding was still intensively developed $[5,6]$. Controled gas nitriding enabled the control and regulation of the growth of the nitrided layer using the changeable value of the nitriding potential. The nitriding potential is very important to control not only the growth kinetics of the diffusion zone, but also the thickness and phase composition of the iron nitride zone (compound zone) [10]. Usually, the nitriding process is carried out at temperatures about $550^{\circ} \mathrm{C}$ [9]. As a consequence of gas nitriding, the two zones usually appear in the surface layer: a compound zone on the top surface and a diffusion zone beneath it [7]. The compound zone consists of intermixed iron nitrides, $\varepsilon(\mathrm{Fe} 3 \mathrm{~N})$ and $\gamma^{\prime}(\mathrm{Fe} 4 \mathrm{~N})$ phases, while the diffusion zone consists of a nitrogen rich solid solution zone with precipitates of nitrides $[8,11,12]$.

In this study, the controlled gas nitriding process was followed by a laser heat treatment. The effect on microstructure, microhardness and tribological behavior was examined and analyzed. Microstructures of the laser-modified gas nitrided specimens were studied by Optical Microscope (OM) and X-ray Diffraction (XRD). Microhardeness measurements were performed using Vickres method. The tribological behavior of the specimens was examined using ball-on-disc tribometer. 


\section{Methods}

$42 \mathrm{CrMo} 4$ steel was used as material of the specimens. The composition of this steel was as follows: $0.38-0.45 \%$ C, $0.9-1.2 \%$ $\mathrm{Cr}$ and $0.15-0.25 \%$ Mo. The samples were prepared in the shape of circular discs with a diameter of $25.4 \mathrm{~mm}$ and thickness of 6 $\mathrm{mm}$. Before nitriding, the specimens were austenitized at $860^{\circ} \mathrm{C}$ $(1123 \mathrm{~K})$, quenched in oil and high-temperature tempered at $600^{\circ} \mathrm{C}(873 \mathrm{~K})$ for 2 hours.

The formation of hybrid surface layers consisted in two steps. At first, the controlled gas nitriding was carried out. Process parameters were as follows: temperature $580^{\circ} \mathrm{C}(853 \mathrm{~K})$, time 8 $\mathrm{h}$ and the changeable nitriding potential. During this process, the selection of nitriding potential was very important because of its influence on the microstructure and the thickness of a white compound zone, including $\varepsilon$ and $\gamma^{\prime}$ nitrides. Next, the Laser Heat Treatment (LHT) was performed using TRUDIODE 3006 diode laser with a nominal power of $3 \mathrm{~kW}$. The laser tracks were arranged as multiple tracks. The laser processing parameters were as follows: scanning rate $(\mathrm{vl}) 2.88 \mathrm{~m} / \mathrm{min}$ and the two values of laser beam power (P): $530 \mathrm{~W}$ and $620 \mathrm{~W}$.

After the controlled gas nitriding and laser modification, the samples were cut perpendicularly to the scanning direction and mounted in a conductive resin. Next, they were polished using the abrasive paper of the different granularity. The specimens were etched with a reagent consisting of $5 \%$ nital in order to reveal the microstructure. Optical microscope OPTA-TECH LAB-40 was used to observe the microstructure. The phase analysis of the fabricated layers was carried out by PANalytical EMPYREAN X-ray diffractometer using $\mathrm{Cu} \mathrm{K} \alpha$ radiation. Microhardness profiles, through the investigated layers, were determined in the polished cross-sections of specimens. The Vickers method was applied for microhardness measurements using the Buehler Micromet II apparatus. The tests were performed under the indentation load of $0.05 \mathrm{kgf}$ (about $0.49 \mathrm{~N}$ ). The wear tests were performed using a ball-on-disc tribometer T-21 (Poznan, Poland). The nitrided $42 \mathrm{CrMo} 4$ steel disc was fixed on a rotating shaft, while the $\mathrm{Al} 2 \mathrm{O} 3$ ball was used as a counter-specimen. The load $\mathrm{Fn}=9.8 \mathrm{~N}$ was applied and the disc rotational speed was equal to $120 \mathrm{~min}-1$. Dry sliding tests were performed. The wear tests lasted $60 \mathrm{~min}$ at a room temperature. The wear rate was calculated as a total linear wear of the sample and counter-sample per hour. After that, the friction coefficient was calculated according to the equation:

$$
\mu=\mathrm{Ff} / \mathrm{Fn}
$$

Where: $\mu$ is friction coefficient, Ff is friction force $(\mathrm{N})$, and Fn is applied load $(\mathrm{N})$.

The wear tracks were observed by optical microscope OM (Poznan, Poland).

\section{Results and Discussion}

The microstructure of $42 \mathrm{CrMo} 4$ steel after controlled gas nitriding process was shown in Figure 1. The nitrided layer was composed of a compound zone with iron nitrides and a diffusion zone. In the compound zone the two regions were visible. A first region contained a porous $\varepsilon\left(\mathrm{Fe}_{3} \mathrm{~N}\right)$ nitrides, occurring at the surface. The second compact region, below this porous zone, contained $\varepsilon+\gamma^{\prime}\left(\mathrm{Fe}_{3} \mathrm{~N}+\mathrm{Fe}_{4} \mathrm{~N}\right)$ nitrides. The thickness of the whole compound zone was about $39 \mu \mathrm{m}$. The diffusion zone, which obtained the depth of approximately $480 \mu \mathrm{m}$, consisted of nitric sorbite with precipitates of $\gamma^{\prime}$ nitrides.

The microstructures of multiple laser tracks after laser modification were shown in Figure 2. In the microstructure, produced with re-melting using laser power beam $P=530 \mathrm{~W}$ and $\mathrm{P}=620 \mathrm{~W}$, the zones were observed as follows: laser re-Melted Zone (MZ), Heat-Affected Zone (HAZ) and a diffusion zone of the nitrided layer without visible effect of laser treatment. The continuous MZ was visible close to the surface. MZ and HAZ were characterized by uniform thickness and homogeneous microstructure. The phase analysis was performed directly after nitriding as well as nitriding and LHT on the treated surfaces. The XRD patterns were obtained using $\mathrm{Cu} \mathrm{K} \alpha$ radiation (Figure $3)$, which allowed to analyze the depth up to $20 \mu \mathrm{m}$. Phase analysis by XRD solely confirmed the presence of $\varepsilon$ iron nitrides in nitrided layer (Figure 3) due to the relatively high depth of this zone (about $20 \mu \mathrm{m}$ ). The microstructure of the re-melted nitrided layer at $\mathrm{P}=530 \mathrm{~W}$ and $\mathrm{P}=620 \mathrm{~W}$ consisted mainly of martensite (identified as $\mathrm{Fe} \alpha$ phase) and an amount of $\varepsilon-\mathrm{Fe}_{3} \mathrm{~N}$ and $\mathrm{FeN}$ iron nitrides. Unfortunately, an amount of $\mathrm{Fe}_{3} \mathrm{O}_{4}$ iron oxides was also identified in re-melted zone.

The microhardness profiles of multiple laser tracks for varying laser processing parameters were shown in Figure 4. The results were compared to the hardness of gas-nitrided layer (before LHT). Multiple laser tracks, produced with re-melting, were characterized by higher hardness compared to the gas-nitrided layer. The toughened and gas-nitrided $42 \mathrm{CrMo} 4$ steel obtained the hardness of $750 \mathrm{HV}$ close to the surface, in compound layer. Next, its hardness gradually decreased to about $340 \mathrm{HV}$ in the toughened substrate. The highest hardness was obtained after producing the multiple tracks at the laser beam power of 530 W. Close to the surface, the hardness was slightly diminished to $650 \mathrm{HV}$ in MZ, and its maximal value in HAZ was equal to 995 HV. Then, the hardness gradually decreased to $330-350 \mathrm{HV}$ in the toughened substrate. In general, the hardness of this hybrid layer was significantly higher than that of only nitrided layer up to about $300 \mu \mathrm{m}$ from the surface. The increase in laser beam power up to $\mathrm{P}=620 \mathrm{~W}$ also caused the diminished hardness close to the surface. Simultaneously, the maximal hardness of $936 \mathrm{HV}$ was observed in the HAZ. The zone with increased hardness in comparison with nitrided layer enlarged up to about $325 \mu \mathrm{m}$ from the surface. Probably, the diminished hardness close to the surface (in MZ) was caused by the relatively low cooling rate in this region during producing the multiple laser tracks. The decrasing temperature in HAZ at higher depths during LHT resulted in changes of microstructure, i.e. in reduced percentage 


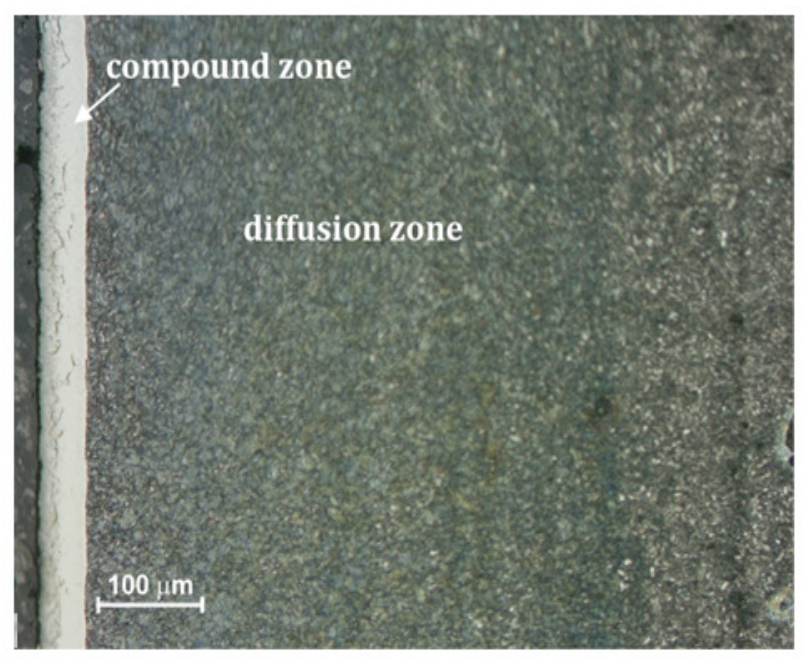

Figure 1: Microstructure of the $42 \mathrm{CrMo} 4$ steel after controlled gas nitriding

a)

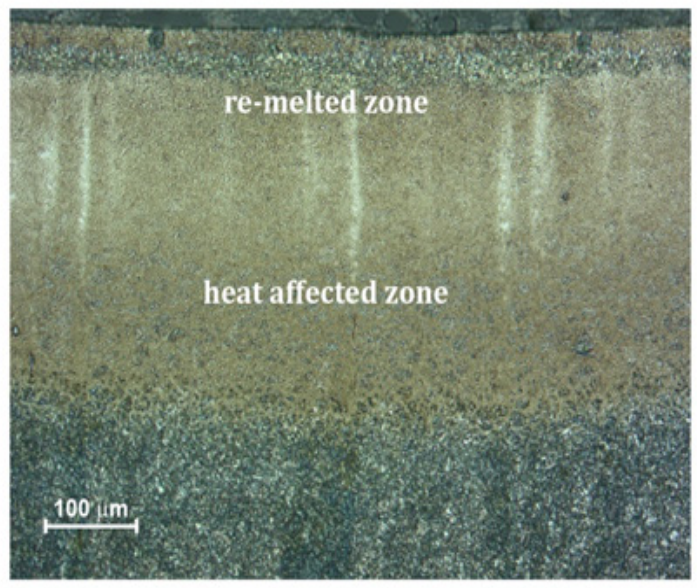

b)

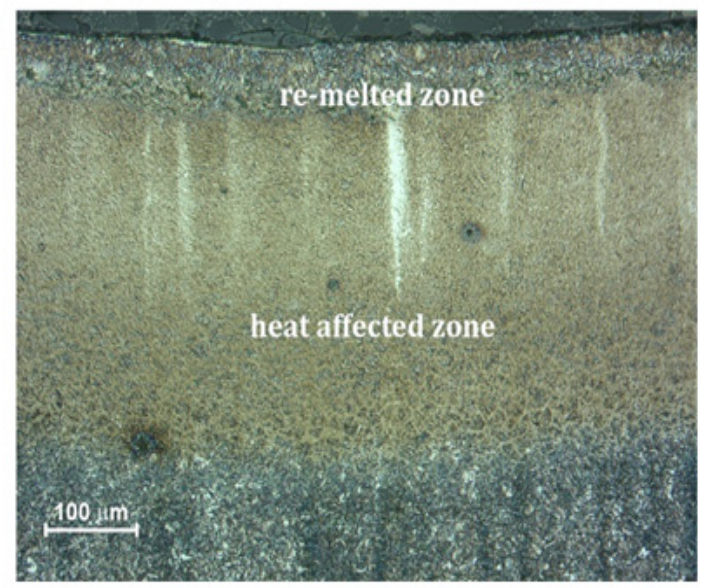

Figure 2: Microstructure of multiple laser tracks produced at $\mathrm{P}=530 \mathrm{~W}$ (a) and $\mathrm{P}=620 \mathrm{~W}$ (b).

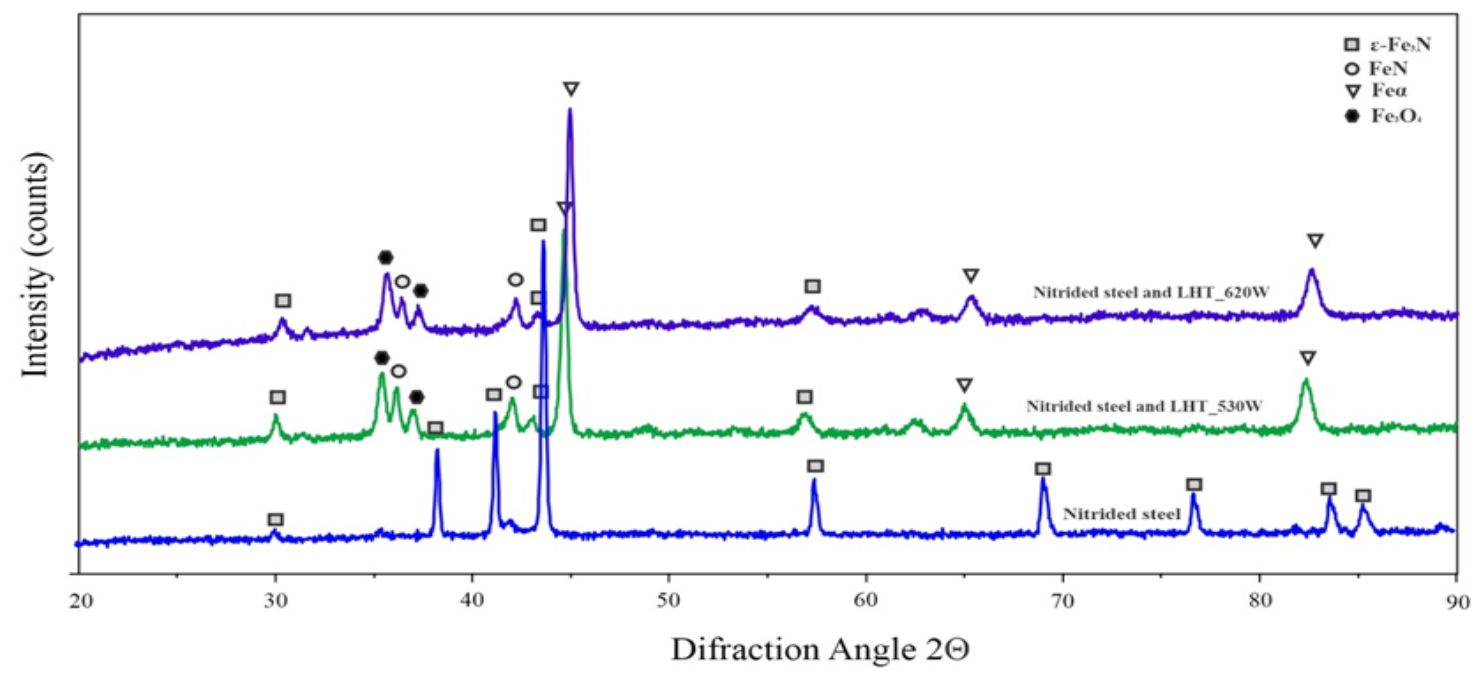

Figure 3: XRD patterns of nitrided layer and nitrided layers after laser heat treatment

Citation: Dominika Panfil-Pryka, Michał Kulka (2021) Mechanical Properties of Nitrided Layer after Laser Modification. SOJ Mater Sci Eng 8(1): 1-6. 
of martensite in HAZ. Therefore, the hardness of HAZ diminished vs. the distance from the surface.

The results of the wear tests of nitrided layer and nitrided layers after laser heat treatment were shown in Figure 5. They lasted 1 hour, and the wear behavior was evaluated using the coefficients of friction. The behavior of nitrided layer differed from that of nitrided layers subjected to LHT. It was clearly visible in Figure 5 showing the friction coefficient vs. the time of friction. The first stage of wear consisted in grinding-in and lasted approximately $300 \mathrm{~s}$ for the nitrided layers after laser heat treatment using laser beam powers $530 \mathrm{~W}$ and $620 \mathrm{~W}$. Then, the course of friction coefficient was very smooth. The measured friction coefficient was equal to 0.60

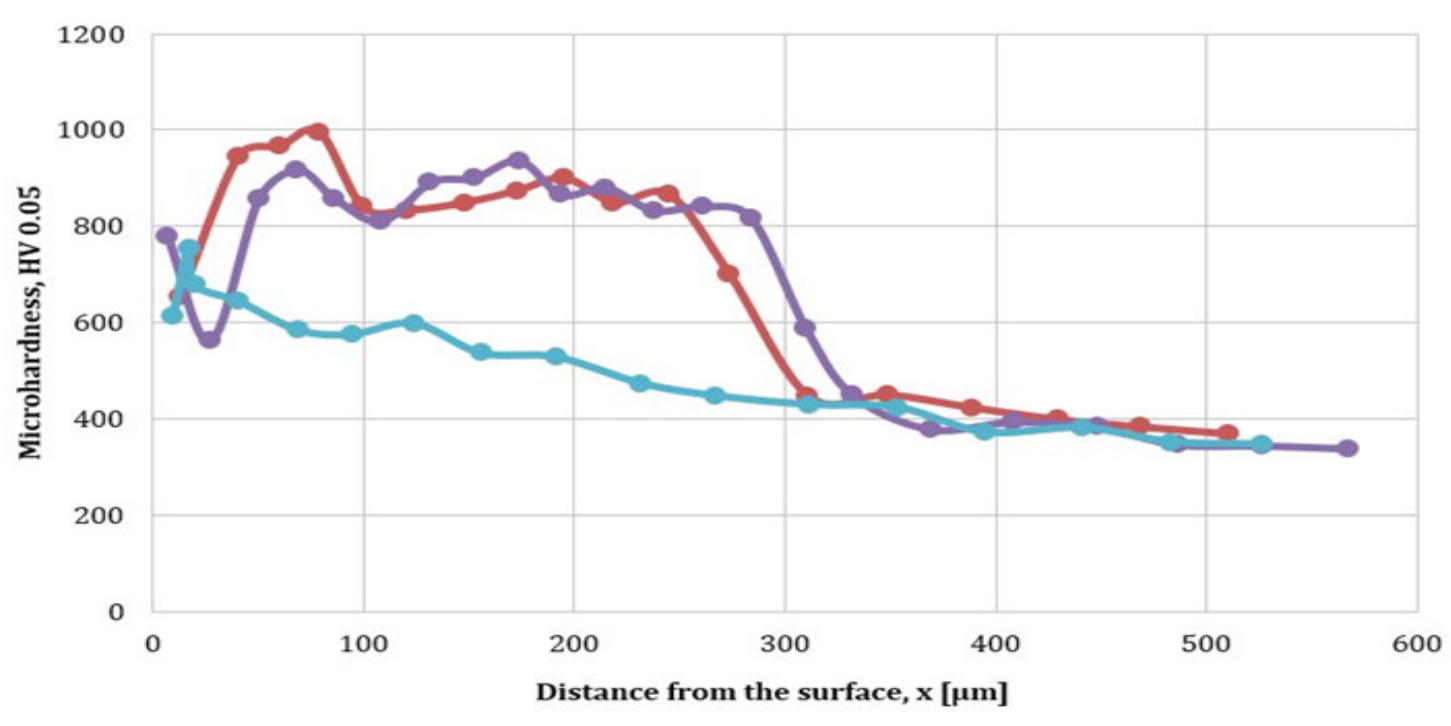

$\longrightarrow$ Nitrided layer and LHT_530W $\quad$ Nitrided layer and LHT_620W $\quad$ Nitrided layer

Figure 4: Hardness profiles of the multiple laser tracks produced on 42CrMo4 steel after gas nitridingcompared to the only nitrided layer.

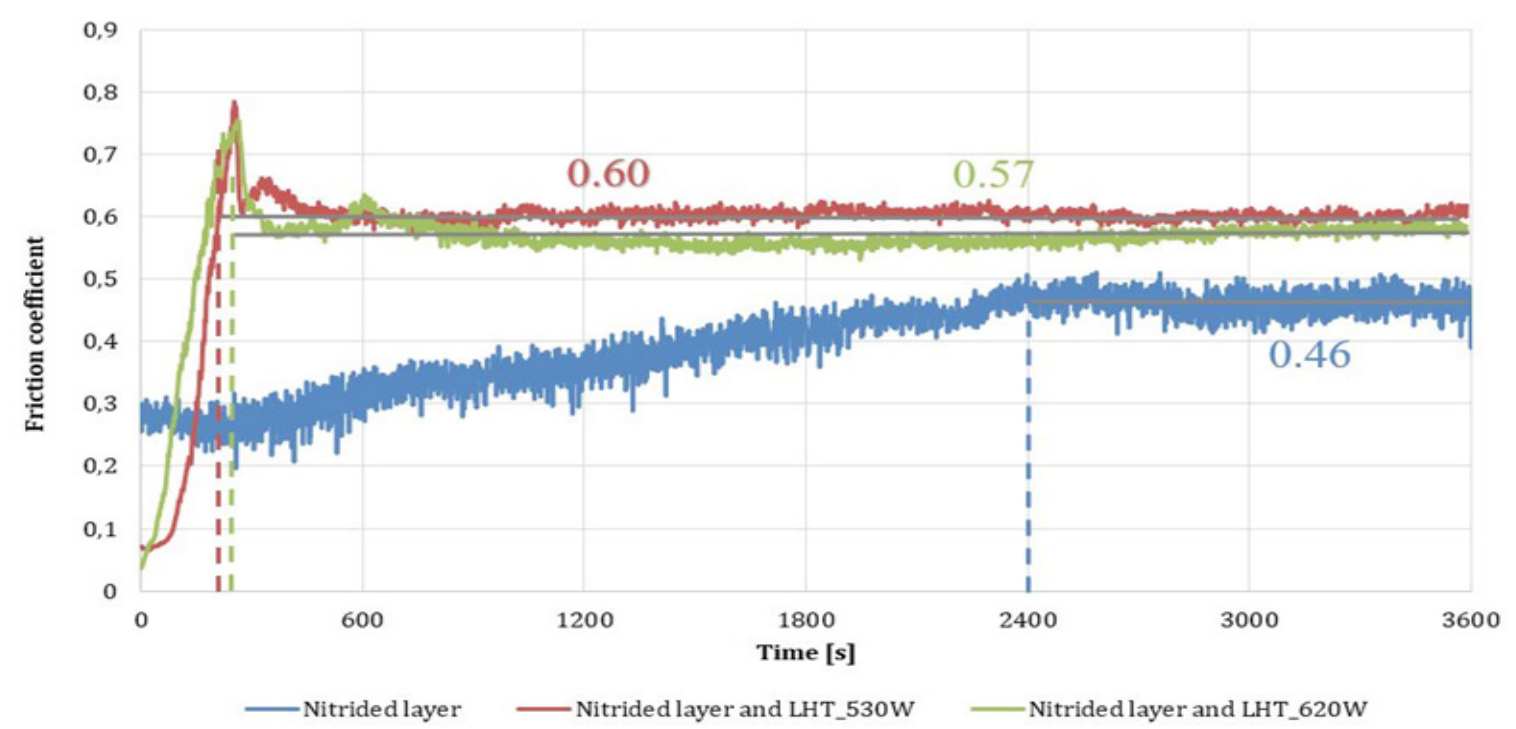

Figure 5: Friction coefficient nitride layer and nitrided layer after laser heat treatment

and 0.57 for the nitrided and laser-modified layers using $\mathrm{P}=530$

$\mathrm{W}$ and $\mathrm{P}=620 \mathrm{~W}$, respectively. The average friction coefficient was calculated taking into account the measurements of friction force after the time of griding-in. In the case of only nitrided layer, the course of friction coefficient was characterized by the large fluctuations, and its value stabilized not before $2400 \mathrm{~s}$. Thus, the grinding-in time was significantly extended. The average value of coefficient of friction was equal to 0.46 . The slightly lower hardness in re-melted zone close to the surface in comparison with the nitrided layer could be the reason for the higher friction coefficients characteristic of hybrid layers. The samples had been intensively machined during the wear process. The OM images of wear tracks were presented in Figure 6. The intensive abrasive wear was confirmed by the presence of shallow grooves for all the 

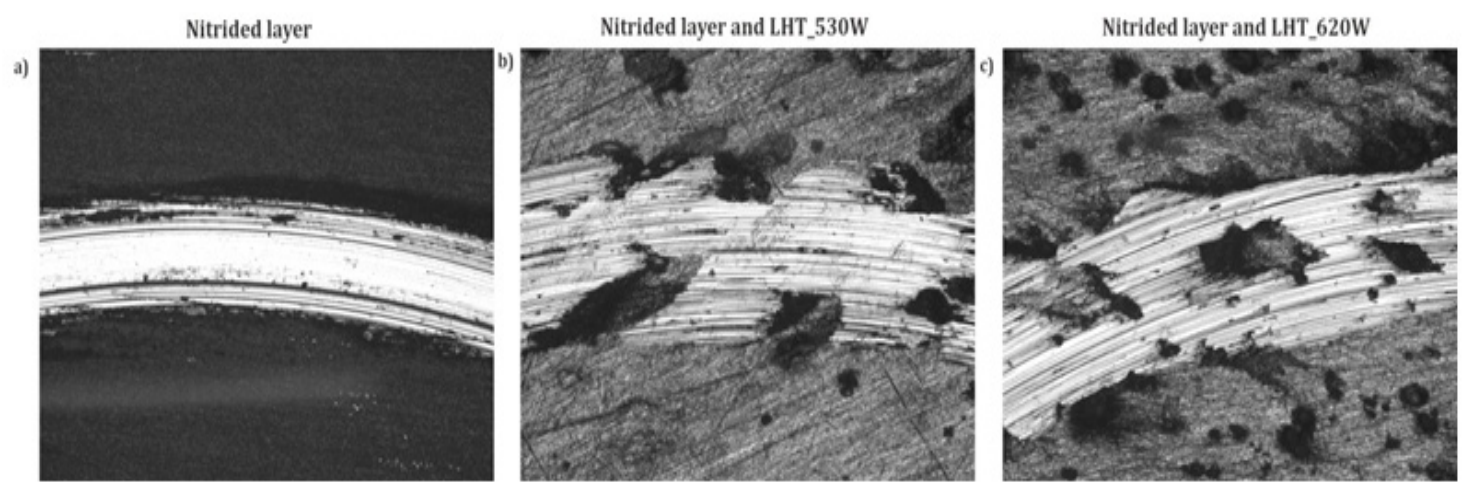

Figure 6: Worn surface of the nitride layer (a), nitride layer after LHT, $P=530 \mathrm{~W}$ (b) and $\mathrm{P}=620 \mathrm{~W}$ (c).

investigated layers. In the case of nitrided layer (Figure 6a), they were relatively uniform. The wear tracks on the surface of lasermodified nitride layers (Figures $6 \mathrm{~b}$ and $6 \mathrm{c}$ ) were characterized by the non-uniform width due to some waviness caused by laser re-melting. In the future, laser beam power should be slightly reduced in order to obtain LHT without re-melting nitrided layer.

\section{Conclusion}

Modification by laser heat treatment was proposed in order to change the microstructure and tribological properties of gasnitrided layer produced on $42 \mathrm{CrMo} 4$ steel. LHT was carried out with re-melting using the two various laser beam powers $\mathrm{P}=530$ $\mathrm{W}$ and $\mathrm{P}=620 \mathrm{~W}$.

Controlled gas nitriding resulted in the formation of compound zone, consisting of $\varepsilon$ nitrides close to the surface and $\varepsilon+\gamma^{\prime}$ nitrides below, as well as a diffusion zone which was composed of nitric sorbite with precipitates of $\gamma^{\prime}$ phase. Laser heat treatment caused a modification of the microstructure and mechanical properties of the surface layer. In the microstructure of hybrid layers, the zones were observed as follows: the remelted zone with nitric martensite and an amount of $\varepsilon$-Fe $3 \mathrm{~N}$ and FeN iron nitrides, the heat-affected zone with nitric martensite and precipitates of $\gamma$ ' phase and the diffusion zone without visible effect of laser treatment (nitric sorbite). The hardness of the remelted zone close to the surface was slightly decreased compared to the hardness of gas-nitrided layer in compound zone. However, the significant increase in hardness was observed in heat-affected zone of each hybrid layer. Hardness of HAZ increased up to 995 HV and up to $930 \mathrm{HV}$ after the LHT using $\mathrm{P}=530 \mathrm{~W}$ and $\mathrm{P}=620 \mathrm{~W}$, respectively. The effect of LHT on the tribological properties was ambiguous. The course of friction coefficient was very smooth after nitriding and LHT. Friction coefficient was equal 0.60 and 0.57 for the hybrid layers, produced using $\mathrm{P}=530 \mathrm{~W}$ and $\mathrm{P}=620$ $\mathrm{W}$, respectively. The wear behavior of the nitrided layer differed from that of hybrid layers (nitrided and laser heat treated). In the case of nitrided layer, the relatively low value of the average friction coefficient was calculated (0.46). However, the course of friction coefficient was characterized by large fluctuations and the extended grinding-in time.

\section{Acknowledgment}

This research was funded by the National Science Centre in Poland, grant number UMO-2016/23/N/ST8/03789.

\section{References}

1. Kusiński J, Kac S, Kopia A, Radziszewska A, Górnikowska M, et al. “Laser modification of thr materials surface layer-a review paper". Bulletin of the Polish Academy of Sceinces Technical Sciences. 2015;4(60):711728.

2. Bojinović M, Mole N, Štok, B. "A computer simulation study of the effects of tempearture change rate on austenite kinetic in laser hardening". Surface \&Coatings Technology. 2015;273:60-76.

3. Safdar S, Li L, Sheikh MA, Liu Z. "An analysis of the effect of laser beam geometry on laser transformation hardening". Journal of Manufacturing Science and Engineering. 2006;128:659-667.

4. Mittemeijer EJ. "Fundamentals of nitriding and nitrocarburizing", In: Dossett J, Totten GE, editors. ASM Handbook: Steel Heat Treating Fundamentals and Processes. 2013;4A:619-646.

5. Sommers M, Mittemeijer EJ. "Layer-growth kinetics on gaseous nitriding of pure iron: evolution of diffusion coefficients for nitrogen in iron nitrides". Metallurgical and Materials Transactions A. 1995;26:57-74.

6. Michalski J, Tacikowski J, Wach P, Ratajski J. “Controlled gas nitriding of $40 \mathrm{HM}$ and $38 \mathrm{HMJ}$ steel grades with and without the surface compound layer, composed of iron nitrides". Maintenance Problems. 2006;2:43-52.

7. Kikuchi S, Komotori J. "Evolution of the gas nitidinh of fine grained AISI 4135 steel treated with fine particle peening and its effect on the tribological properties". Materials Transactions. 2015;56(4):556-562. 
8. Mashreghi AR, Soleimain SMY, Saberifar S. The investigation of wear and corrosion behavior of plasma nitride DIN 1.2210 cold work tool steel“. Materials and Design. 2013;46:532-538.

9. Baranowska J, Franklin SE, Pelletier CGN. "Tribological behavior and mechanical properties of low temperature gas nitride austenitic steel in relation to layer morphology". Wear. 2005;259:432-438.

10. Michalski J, Wach P, Tacikowski J, Betiuk M, Burdyński K, et al. "Contemporary Industrial Application of Nitriding and Its Modifications". Mater Manuf Process. 2009;24:855-858.
11. Almeida EAS, Milan JCG, Costa CE. "Acquired properties comparison of solid nitriding, gas nitriding and plasma nitriding in tool steels". Materials Research. 2015;18(1):27-35.

12. Panfil D, Kulka M, Wach P, Michalski J, Przestacki D. “Nanomechanical properties of iron nitrides produced on $42 \mathrm{CrMo} 4$ steel by controlled gas nitriding and laser heat treatment". J Alloys Compd. 2012;706:6375 